\title{
Effects of studying sequences of process-oriented and product-oriented worked examples on troubleshooting transfer efficiency
}

Citation for published version (APA):

Van Gog, T., Paas, F., \& Van Merriënboer, J. (2008). Effects of studying sequences of process-oriented and product-oriented worked examples on troubleshooting transfer efficiency. Learning and Instruction, 18(3), 211222. https://doi.org/10.1016/j.learninstruc.2007.03.003

DOI:

10.1016/j.learninstruc.2007.03.003

Document status and date:

Published: 01/06/2008

Document Version:

Peer reviewed version

Please check the document version of this publication:

- A submitted manuscript is the version of the article upon submission and before peer-review. There can be important differences between the submitted version and the official published version of record. People interested in the research are advised to contact the author for the final version of the publication, or visit the DOI to the publisher's website.

- The final author version and the galley proof are versions of the publication after peer review.

- The final published version features the final layout of the paper including the volume, issue and page numbers.

Link to publication

\section{General rights}

Copyright and moral rights for the publications made accessible in the public portal are retained by the authors and/or other copyright owners and it is a condition of accessing publications that users recognise and abide by the legal requirements associated with these rights.

- Users may download and print one copy of any publication from the public portal for the purpose of private study or research.

- You may not further distribute the material or use it for any profit-making activity or commercial gain

- You may freely distribute the URL identifying the publication in the public portal.

If the publication is distributed under the terms of Article 25fa of the Dutch Copyright Act, indicated by the "Taverne" license above, please follow below link for the End User Agreement:

https://www.ou.nl/taverne-agreement

Take down policy

If you believe that this document breaches copyright please contact us at:

pure-support@ou.nl

providing details and we will investigate your claim.

Downloaded from https://research.ou.nl/ on date: 26 Apr. 2023 
1Running head: WORKED EXAMPLES SEQUENCING

This is a pre-print of: Van Gog, T., Paas, F., \& Van Merriënboer, J. J. G. (2008). Effects of studying sequences of process-oriented and product-oriented worked examples on troubleshooting transfer efficiency. Learning and Instruction, 18, 211-222.

Copyright Elsevier; available online at http://www.elsevier.com/wps/find/journaldescription.cws home/956/description\#description

Effects of Studying Sequences of Process-Oriented and Product-Oriented Worked Examples on Troubleshooting Transfer Efficiency

Tamara van Gog ${ }^{a}$, Fred Paas ${ }^{\text {a, b }}$, and Jeroen J. G. van Merriënboer ${ }^{\text {a }}$

${ }^{a}$ Educational Technology Expertise Center, Open University of The Netherlands

${ }^{\mathrm{b}}$ Psychology Department, Erasmus University Rotterdam, The Netherlands

Author note:

Correspondence concerning this article should be addressed to Tamara van Gog, Open University of the Netherlands, Educational Technology Expertise Centre, P.O. Box 2960, 6401 DL, Heerlen, The Netherlands. Phone: +31 45 5762276, Fax: + 3145 5762907, E-mail: tamara.vangog@ou.nl.

This research project was funded by the Netherlands Organization for Scientific Research (NWO, The Hague, project no. 411-01-010).

The authors would like to thank Ivo Hamers and Jan Gielen for their help with organizing this study, Mihály Koltai of DesignSoft, Inc. for making the TINA Pro software available free of charge for this study, and the three anonymous reviewers for their helpful comments. 


\begin{abstract}
Whereas product-oriented worked examples only present a problem solution, process-oriented worked examples additionally explain the rationale behind the presented solution. Given the importance of understanding this rationale for attaining transfer, process-oriented worked examples would be expected to result in more efficient transfer. However, a previous study in the domain of electrical circuits troubleshooting suggested an expertise reversal effect: Process information might initially impose an effective cognitive load and lead to higher efficiency but may become redundant and impose an ineffective load when training progresses, which hampers efficiency. The present study confirmed this hypothesis. The results are discussed in terms of theoretical and practical implications for the design of optimal training sequences for complex cognitive tasks.
\end{abstract}


Effects of Studying Sequences of Process-Oriented and Product-Oriented Worked Examples on Troubleshooting Transfer Efficiency

A large body of research has demonstrated that for novices, engaging in problem solving is not an effective way to acquire problem-solving skill. Studying worked examples in the initial phases of cognitive skill acquisition is more effective than solving problems. This consistent finding is referred to as the "worked example effect" (for overviews, see Atkinson, Derry, Renkl, \& Wortham, 2000; Sweller, Van Merriënboer, \& Paas, 1998). Cognitive load theory (Sweller, 1988; Sweller et al., 1998; Van Merriënboer \& Sweller, 2005) explains the worked example effect in terms of reduced extraneous, or ineffective working memory load, which allows for better schema construction and automation.

\section{Cognitive Load Theory and Learning from Worked Examples}

The central tenet of cognitive load theory is that in order to be effective for schema construction and automation, instruction should be designed in a way that takes into account the structures that constitute human cognitive architecture. Working memory (WM) capacity is considered limited to seven plus or minus two elements or chunks of information (Miller, 1956) when merely holding, and even less when processing new information elements (Cowan, 2001). Complex tasks contain a high number of interactive information elements. When learning complex tasks, these elements are new, and because they are interactive have to be processed simultaneously in WM for learning to commence (Chandler \& Sweller, 1991). Consequently, such tasks will impose a high WM load. This cognitive load imposed by the interactive elements a task contains is called intrinsic cognitive load (Sweller et al., 1998). Intrinsic cognitive load is influenced by the prior knowledge of the learner, in such a way that when learning progresses, information elements are combined into schemata that can be treated as one element in WM. Hence, the higher the prior knowledge of a learner, the lower the intrinsic load a task imposes. 
Troubleshooting tasks are an example of complex tasks that impose a high intrinsic cognitive load on novice learners. Information on circuit type (parallel, series, mixed), components (function, relation to other components), physics laws (Ohm's law, Kirchoff's laws), and measurements taken on the system have to be processed in WM simultaneously in order to be able to diagnose the fault/s in the circuit (see for a more elaborate discussion Van Gog, Paas, \& Van Merriënboer, 2006). Next to the process of schema acquisition, the process of schema automation (Schneider \& Shiffrin, 1977) further reduces cognitive load by allowing learners to bypass the limited capacity WM. By using automated schemas, learners have to invest less mental effort to reach an optimum level of performance (i.e., the relationship between effort and performance weakens with practice; Paas \& Van Merriënboer, 1993; Yeo \& Neal, 2004).

In addition to intrinsic cognitive load, there is load imposed by cognitive processes induced through the design of instruction. This type of cognitive load is called extraneous when it is ineffective for learning and germane when it is effective for learning. According to Sweller et al. (1998), learning can take place through solving problems with weak strategies such as meansends analysis that novice learners often employ, but this will be a slow and sub-optimal process. Although means-ends analysis is effective for obtaining solutions to problems, it imposes a relatively high extraneous load and consequently reduces the cognitive resources available for learning (i.e., schema acquisition and automation). Particularly, under conditions of high intrinsic load, the use of these strategies can easily overload WM, which does not foster learning. Studying worked examples reduces the extraneous load, because learners do not have to devote cognitive resources to weak problem-solving strategies; instead they can invest all available resources in studying the solution and constructing and automating a cognitive schema for solving such problems.

For a long time, research inspired by cognitive load theory has searched for instructional 
formats such as worked examples that would reduce extraneous cognitive load. However, in recent years, it was realized that it would be fruitful to search for instructional formats that not only reduce extraneous load, but simultaneously stimulate learners to invest cognitive capacity in processes that are effective for learning (i.e., impose a germane load; Sweller et al., 1998; Paas, Renkl, \& Sweller, 2003). Strategies that are known to increase germane cognitive load induced by worked examples are for example increasing variability (Paas \& Van Merriënboer, 1994), or contextual interference (Van Merriënboer, Schuurman, De Croock, \& Paas, 2002) in the delivery of worked examples during practice.

\section{Measuring Cognitive Load: Mental Effort and Mental Efficiency}

There are different subjective and objective techniques available for measuring cognitive load (see Paas, Tuovinen, Tabbers, \& Van Gerven, 2003). Investment of mental effort is considered to reflect the actual cognitive load allocated to task performance (Paas et al., 2003). Subjective mental effort rating scales, such as the nine-point scale developed by Paas (1992) are easy to use, and subjective measures have been shown to be reliable (Paas et al., 2003; Yeo \& Neal, 2004). The nine-point rating scale is also sensitive: It has been shown to detect fluctuations in intrinsic load (Ayres, 2006).

However, many studies inspired by cognitive load theory do not actually measure cognitive load. This is problematic, because two learners may reach similar performance scores, but with very different levels of mental effort invested in the learning phase or in reaching that level of performance in the test phase. In the test phase, cognitive load measures in combination with performance measures will provide more detailed insight into the level of schema acquisition and automation than performance measures alone (Paas \& Van Merriënboer, 1993; Yeo \& Neal, 2004). Paas and Van Merriënboer (1993) developed a measure of mental efficiency based on standardized performance and mental effort scores on transfer test items, which reflects 
the quality of learning (i.e., the extent of schema construction and automation) resulting from a particular instructional condition. Note though, that this measure has often been adapted to one that incorporates effort invested during the learning phase instead of on the test, and that this adapted measure as such is not indicative of the quality of schemata. It can, however, say something about the quality of instruction: If learners studying instructional format $\mathrm{A}$ are able to reach similar learning outcomes (as indicated by the original efficiency measure) to those studying format $\mathrm{B}$, but format $\mathrm{A}$ requires less effort during learning, than it is more learnerfriendly to implement format A in the classroom (see also Paas \& Van Gog, 2006). Increasing Germane Cognitive Load and Efficiency: Process-Oriented Worked Examples

Worked examples typically show a problem state, a goal state, and the solution steps that lead from the problem state to the goal state (i.e., the solution procedure). They show how to obtain a product (final solution), but do not express the knowledge involved in the process of problem solving. This is problematic, because knowing a procedure is not enough to understand it, and understanding is necessary for attaining transfer; especially far transfer (Gott, Parker-Hall, Pokorny, Dibble, \& Glaser, 1993; Mayer \& Wittrock, 1996; Ohlsson \& Rees, 1991). Understanding involves both principled knowledge about objects and events in that domain, the purpose of the steps in a procedure, and the strategic knowledge (i.e., the heuristics and/or a systematic approach to problem solving that is used) used in selecting the steps in a procedure (see Ohlsson \& Rees, 1991; Van Gog, Paas, \& Van Merriënboer, 2004). Without understanding, procedures tend to contain more errors and are more easily forgotten, and it is very difficult to recognize and flexibly apply the relevant parts of a previously learned procedure for solving novel problems, that is, for transfer (Gott et al., 1993; Ohlsson \& Rees, 1991).

It seems that in some cases this lack of principled and strategic knowledge underlying the solution procedure (i.e., the rationale) in typical, product-oriented, worked examples can be 
compensated for by students' self-explanations of the rationale behind the solution steps, which can enhance transfer performance (Atkinson, Renkl, \& Merrill, 2003; Chi, Bassok, Lewis, Reimann, \& Glaser, 1989). However, it is also known that some students are unable to provide adequate self-explanations (see Chi et al., 1989; Renk1, 1997); especially very early in training students may lack the domain knowledge necessary to do so. It has therefore been argued that in initial training students may benefit from studying process-oriented worked examples that not only show the solution steps, but also expressly state the rationale behind those steps (Van Gog, et al., 2004). Studying those process-oriented worked examples would stimulate learners' construction and automation of cognitive schemata during training, which would subsequently allow for more efficient transfer performance than studying product-oriented worked examples.

Process-oriented worked examples show some resemblance to worked examples containing instructional explanations, which also convey principled knowledge about the purpose of the steps in a procedure. However, process-oriented worked examples differ in the sense that they not only include principled information, but also strategic information (heuristics and systematic approaches to problem solving). The importance of strategic information becomes more pronounced when tasks have multiple possible solution paths, for which one needs a strategy to narrow the search space and select those operators that are most likely to lead to a solution.

Instructional explanations have mainly been studied as an alternative for selfexplanations, however, many studies failed to find positive effects on learning and/or transfer of providing instructional explanations in worked examples (Gerjets, Scheiter, \& Catrambone, 2006; Große \& Renkl, 2006; Renkl, 2002). Different explanations have been given for the lack of effects of instructional explanations. For example, students may not attend to this information, or as Renkl (2002) proposed, the explanations may not be adapted well enough to the learners' 
prior knowledge, they may be poorly timed, or it may simply be an effect of self-generated information being remembered better. Another explanation is suggested by the work of Kieras and Bovair (1984), who suggested that providing users with explanations about the functioning of a device might not be necessary when the device that they have to operate is very simple, because it is easy for users to infer. Possibly this applies to problem categories as well, in which case adding principled information to problems on which the principles are relatively easy to infer may not have a beneficial effect.

Results of a recent experiment on the effects of process-oriented worked examples in the domain of electrical circuits troubleshooting did not show the expected beneficial effects on learning either (Van Gog et al., 2006). In fact, these results suggested lower efficiency of transfer for students who had received a training consisting entirely of process-oriented worked examples than for students who had had a training consisting entirely of product-oriented worked examples. This suggestion is confirmed by a re-analysis of the Van Gog et al. data using Paas and Van Merriënboer's (1993) efficiency procedure: A planned contrast showed that studying process-oriented worked examples $(M=-.15, S D=.98)$ resulted in lower efficiency than studying product-oriented worked examples $(M=.70, S D=1.05), t(57)=2.56, p<.01$ (onetailed), $d=.84$ (large effect size). The present experiment intends to investigate a possible explanation for this finding, and one that might apply to worked examples providing instructional explanations as well, that is, the occurrence of an "expertise reversal effect" (Kalyuga, Ayres, Chandler, \& Sweller, 2003; Kalyuga, Chandler, Tuovinen, \& Sweller, 2001; Leahy \& Sweller, 2005). The Expertise-Reversal Effect

Studies on the expertise reversal effect show the influence of students' prior knowledge on the effectiveness of instructional formats. Formats that are effective for learning when 
students have little or no prior knowledge may be less effective or ineffective for students with more knowledge, and vice versa. The instructional guidance that fosters learning when no problem schemata are available yet (low prior knowledge) may start to interfere with learning when students have already developed schemata. The available schemata make the guidance redundant, however, redundant information is hard to ignore. So some of the WM capacity is allocated to redundant information already incorporated in schemata, which leads to suboptimal learning processes (Kalyuga et al., 2003). For example, Kalyuga et al. (2001) found that studying (product-oriented) worked examples was effective for students with no prior knowledge, but that the worked-out solution steps were redundant for students with more prior knowledge, who benefited more from solving problems themselves instead of studying worked out solutions. The redundant information contained in the worked examples no longer contributed to learning and could even hamper learning for high prior knowledge students. In other words, the expertise reversal effect indicates that what may reduce extraneous load for a novice learner, may actually increase extraneous load for a more advanced learner. The expertise reversal effect can also occur with formats that induce a germane load for students with more prior knowledge, but impose extraneous load for low prior knowledge students, as the imagination effect shows: Whereas imagining the procedure was effective for learning for students with high prior knowledge, it was ineffective for students with no prior knowledge, who benefited more from studying worked examples (Cooper, Tindall-Ford, Chandler, \& Sweller, 2001).

However, not only prior knowledge is important. Because knowledge increases also during the learning phase, it may be the case that instructional formats that are effective in the beginning of this phase, may no longer be effective later on, and in some cases, may even start to hamper learning. This also explains why completion (Van Merriënboer \& Krammer, 1990) or fading (Renkl \& Atkinson, 2003) strategies, in which students first study fully worked-out 
(product-oriented) examples, then complete steps in problems with "blanks", and finally solve problems without any instructional support, have been found to be more effective than learning by examples only or problem solving only.

This increase in knowledge during the learning phase, may have led to an expertise reversal effect in the Van Gog et al. (2006) experiment: Adding process information to worked examples might initially impose a germane load and lead to higher efficiency, but it may become redundant, impose an extraneous load, and start to hamper learning when training progresses and knowledge increases.

\section{Aim and Hypotheses of the Present Study}

Although the data of the Van Gog, et al. (2006) experiment suggest an expertise reversal effect, it is not possible to corroborate this hypothesis based on their data. In that study, only one training phase was offered and one test was taken, so there is no way to establish whether the process-oriented worked examples were effective initially but (i.e., learning outcomes were not measured halfway through the training). Moreover, the training for each student consisted of one instructional format only (which varied per condition; i.e., studying only product-oriented worked examples or process-oriented worked examples). To demonstrate that an expertise reversal effect indeed occurs, at least two measures of learning outcomes (halfway through and at the end of the learning phase) are needed and it would be helpful if it could be shown that removing the redundant information would lead to continuing increases in learning. That is, process-oriented worked examples would not only be expected to be more effective in the beginning of the training, but removing the redundant information (i.e., offering product-oriented worked examples) should lead to further enhancement of efficiency.

Hence, in the present experiment a repeated measures design is applied in which participants receive two short training sessions each followed by a transfer test. The first training 
session either requires participants to study product-oriented worked examples or processoriented worked examples, followed by a second training session, in which participants were required to study the same worked example format (i.e., a product-product or process-process sequence) or a different worked example format (i.e., a product-process or process-product sequence).

It is hypothesized that studying process-oriented worked examples would initially lead to higher efficiency on transfer tasks. That is, on the first test the process-process and processproduct conditions are expected to have a higher efficiency score than the product-product and product-process conditions (Hypothesis 1). However, once learners have gained understanding of the solution procedure, continuing to offer process information would lead to redundancy and lower efficiency on transfer tasks, whereas removing this information by offering productoriented worked examples would continue to enhance efficiency. That is, on the second test, the process-process condition would have a lower efficiency than the process-product condition (Hypothesis 2a). In addition, on the second test, efficiency of the process-product condition would be expected to be higher than that of the product-product or product-process conditions (Hypothesis 2b).

\section{Method}

\section{Participants}

Participants were 82 fifth-year secondary education students (of the highest level of secondary education in The Netherlands) with physics in their curriculum (age $M=16.10$ years, $S D=.49 ; 40$ male, 42 female). They received $€ 7.50$ for their participation. They had studied the basics of electrical circuits (component functions, circuit types, Ohm's and Kirchoff's laws), but had no experience with applying that knowledge to troubleshooting.

\section{Design}


A repeated measures design was used, in which participants studied two series of training worked examples each followed by a series of transfer test problems. The conditions, to which participants were randomly assigned before the experiment, were: Product-product $(n=21)$, process-process $(n=21)$, product-process $(n=20)$, and process-product training sequences $(n=$ 20).

\section{Materials}

The types of training and test tasks, and the performance and mental effort measures on which the efficiency measure is based are similar to those used by Van Gog et al. (2006).

Prior knowledge questionnaire. A prior knowledge questionnaire, consisting of seven open-ended questions on troubleshooting and parallel circuits principles, was administered, with a maximum total score of 10 points. Examples of items are "What do you know about the total current in parallel circuits?", "What is probably going on if you do not measure any current in a parallel branch of the circuit?".

Introduction. An introduction to the TINA Pro software, version 6.0 (TINA = Toolkit for Interactive Network Analysis; DesignSoft, Inc., 2002) was provided on paper, together with an "introduction practice circuit" in TINA on which students could try out the functioning of the program as described in that introduction (how to take measurements, repair components, etc.).

Training examples. The training examples (two series of four) consisted of malfunctioning parallel electrical circuit simulations in TINA for which either a worked-out solution (product-oriented; Figure 1) or a worked-out solution plus process information (processoriented; Figure 2) was provided. The process-oriented worked examples contain the same steps as the product-oriented worked examples, but additionally contain principled information printed in italics, and an expressly stated systematic problem approach in bold. Four types of faults occurred in the circuits: A resistor could be open, shorted, its value could have changed to a 
higher one than indicated in the circuit diagram, or to a lower one than indicated in the diagram. Each training task contained one fault and each type of fault occurred once in each series, but not in a fixed order.

Test problems. The test problems (two series of four) consisted of malfunctioning electrical circuit simulations in TINA that participants had to troubleshoot without any further information available. Each series consisted of two near transfer problems and two far transfer problems. The near transfer problems had similar structural, but different surface features than the training tasks, whereas the far transfer problems had dissimilar structural features as well, that is, these contained a different fault or consisted of a different type of circuit. As an example, a near transfer task could be a parallel circuit such as those presented in Figures 1 and 2, with similar faults as in the training examples (resistor open, shorted, or changed in value). A far transfer task could be a mixed circuit (i.e., series and parallel) with a trained fault (resistor open, shorted, or changed in value) or a parallel circuit with a new fault such as a defect voltage source. In each series, one near and one far transfer problem contained one fault, and one near and one far transfer problem contained two faults. The reliability of the transfer tests was .66 (Cronbach's alpha).

Efficiency measure. On pre-printed answer sheets, participants were instructed to write down for each test problem which components were faulty, and to indicate what the fault in the components was by selecting it from a list: The component: a) "is open", b) "is shorted", c) "has changed value: from ... [given in diagram] to ... [calculated based on measurements]", or d) "I do not know". They were instructed to fill out the values when they indicated 'c'. For each correctly diagnosed faulty component 1 point was given and for correct diagnosis of the fault in that component 1 point was given (and in case 'c' was indicated, but the values were wrong, $1 / 2$ point was given). So the maximum mean score over the four test tasks was 3:2 points could be 
obtained for each of the two tasks with one fault, and 4 for each of the two tasks with two faults, this gives a cumulative maximum score of $12([2 \times 2]+[2 \times 4]=4+8=12)$ and a mean maximum score of $3(12 / 4=3)$.

Participants were instructed to indicate after each training example how much mental effort they invested in studying it, and after each test problem how much mental effort they invested solving it, on a 9-point rating scale (Paas, 1992), ranging from 1 "very, very low effort" to 9 "very, very high effort".

Participants' performance (P) and mental effort (E) scores on the transfer tests were

standardized, and the mean $z$-scores were entered into the formula $\frac{P-E}{\sqrt{2}}$ to obtain the efficiency score (Paas \& Van Merriënboer, 1993).

Time-on-task. In the Teacher-Supervisor module, the TINA Pro software logged the timeon-task.

\section{Procedure}

The study was run in three sessions. Per session, participants were equally distributed across conditions (session 1: $n=16,4$ per condition; session 2: $n=46,12$ in conditions 1 and 2, and 11 in conditions 3 and 4; session 3: $n=20,5$ per condition). Participants were instructed to fill out the prior knowledge questionnaire first, after which they could familiarize themselves with TINA by reading the introduction and trying functionalities on the "introduction practice circuit". When all participants had finished the introduction and had no more questions regarding the program, they were allowed to start studying the first series of training examples (either product or process-oriented worked examples). After studying each training example, participants indicated the amount of effort they invested in studying it on the 9-point rating scale. 
After the first series of training examples, they completed the first series of test problems, for each problem indicating the faulty component/s and the type of fault/s, as well as the mental effort invested in solving it, on the answer sheets. Then, they studied the second series of training examples (either product or process-oriented worked examples), and completed the second series of test problems in the same way. Participants could work at their own pace, and were allowed to use a calculator when solving the test problems, to ensure that simple computational errors would not affect performance.

\section{Results}

Means and standard deviations per condition of prior knowledge, efficiency, and time-ontask, are provided in Table 1 (and those data are also given for the performance and mental effort scores on which the efficiency measure is based). A significance level of .05 is used for the analyses reported here, and Cohen's $d$ is provided as an estimate of effect size, with $d=.20$ corresponding to a small effect, $d=.50$ to a medium, and $d=.80$ to a large effect (Cohen, 1988). One participant (male; process-process condition) was excluded from the analyses because he did not fill out $70 \%$ of the test answers and mental effort ratings. One participant in the productproduct condition did not fill out the prior knowledge questionnaire.

An ANOVA on the prior knowledge scores revealed no significant differences in prior knowledge between the conditions $F(3,76)<1$, ns.

In line with our first hypothesis, a t-test showed that efficiency on the first transfer test was higher for students who had studied process-oriented worked examples $(M=.24, S D=1.05)$ than for students who had studied product-oriented worked examples $(M=-.24, S D=1.04)$, $t(79)=2.07, p<.05$ (one-tailed), $d=.46$. Time-on-task (min.) invested in the first training did not differ significantly between those groups, $t(79)=.054, n s$ (process-oriented worked examples: $M=3.41, S D=.61$; product-oriented worked examples: $M=3.40, S D=.62$ ). Neither 
did time-on-task invested in the first test, $t(79)=.084, n s$ (process-oriented worked examples: $M$ $=4.96, S D=1.24$; product-oriented worked examples: $M=4.93, S D=1.46$ ).

Planned contrasts of the efficiency on the second transfer test show that, in line with our hypothesis (2a), the process-product condition had a higher efficiency than the process-process condition, $t(77)=1.67, p<.05$ (one-tailed), $d=.50$, and that, contrary to our hypothesis $(2 \mathrm{~b})$, the process-product condition did not have a significantly higher efficiency on the second test than the product-product and product-process conditions $t(77)=.727, n s$. An ANOVA showed that time-on-task (min.) invested in the second training differed significantly between conditions, $F$ $(3,77)=5.517, M S E=.359, p<.01, d=.92$. A post-hoc Tukey test showed that time-on-task was significantly higher in the product-process condition than in the product-product and process-product conditions $(\mathrm{p}<.05)$. Time-on-task invested on the second test did not differ significantly between conditions $F(3,77)<1, n s$.

\section{Discussion}

Our hypothesis that studying process-oriented worked examples would initially impose a germane cognitive load, resulting in higher efficiency on the first test than studying productoriented worked examples, was confirmed with a medium effect size. Also in line with our hypothesis, and also a medium-sized effect, was that the process information became redundant, imposing an extraneous load that started to hamper learning: Continuing to study processoriented worked examples led to lower efficiency on the second test than continuing with product-oriented worked examples. As the analyses show, those results are not likely to be artifacts of differences between groups in prior knowledge or in time-on-task invested in training and the test. These findings are consistent with the expertise reversal effect (Kalyuga et al., 2003). Higher efficiency, that is, equal or higher transfer performance with less investment of effort required to attain that transfer performance was reached by students in the process-oriented 
worked examples conditions than by students in the product-oriented worked examples conditions. However, once students had learned the process information, that is, incorporated it into their schemata, it became redundant and continuing to offer this information started to hamper learning.

Contrary to our expectation, however, the efficiency of the process-product condition on the second test was not significantly higher than that of the product-product or product-process conditions. This is rather puzzling. Even though starting with studying product-oriented worked examples leads to lower efficiency on the first test than starting with process-oriented worked examples, students who started with product-oriented worked examples seemed to be able to "close the gap" on the students in the process-product sequence on the second test, whether they studied process-oriented or product-oriented worked examples during the second training phase (though studying process-oriented worked examples during the second training phase when product-oriented worked examples were studied in the first training phase, did require some more time). A possible explanation is that even though process-oriented worked examples led to higher efficiency, that is, higher quality of developed schemata, the product-oriented worked examples enabled students to develop schemata of enough quality to fully benefit from the second training session. Another possible explanation is that students in the process-product sequence should have been able to self-explain the rationale they learned while studying processoriented worked examples when they received the product-oriented worked examples in which it was absent, but did not do so unsolicited. Had they done so, this might have led to significantly higher efficiency. Future research is necessary to study these possible explanations; it would, for example, be interesting to investigate whether after initial provision of process-oriented worked examples, combining product-oriented worked examples with self-explanation prompts (cf. Atkinson et al., 2003; Renkl, 1997) would be more efficient than providing product-oriented 
examples without such prompts. Furthermore, acquiring verbal protocols (Ericsson \& Simon, 1993; Van Gog, Paas, Van Merriënboer, \& Witte, 2005) in such future studies might shed light on how students actually respond to the different levels of instructional guidance in these different example sequences.

As mentioned in the introduction, process-oriented worked examples show some resemblance to worked examples containing instructional explanations, which also convey principled knowledge about the purpose of the steps in a procedure, but differ in the sense that they emphasize not only domain principled, but also strategic knowledge underlying the selection of solution steps. Nevertheless, the expertise reversal effect explanation put forward here based on the results of Van Gog et al. (2006) combined with those of the present study, might also explain why studies on instructional explanations or elaborations in worked examples often fail to find positive effects on learning and transfer (see e.g., Gerjets et al., 2006; Große \& Renkl, 2006; Renkl, 2002). Since those studies did not measure mental effort, or used a dissimilar instrument and procedure for doing so, it is not possible to corroborate this assumption with a reanalysis of those data, but it seems plausible.

As for practical implications, the results of this study should be regarded in perspective with previous findings on the interaction between instructional guidance and knowledge and expertise. As mentioned in the introduction, one of the effective instructional strategies that takes into account increases in knowledge during the learning phase is a completion (Van Merriënboer \& Krammer, 1990) or fading (Atkinson et al., 2003; Renkl \& Atkinson, 2003) strategy, in which students first study fully worked-out (product-oriented) examples, then complete steps in problems with "blanks", and finally solve problems without any instructional support. In combination with the present findings, this suggests that an optimal training sequence for novices would likely proceed from studying process-oriented worked examples, studying product- 
oriented worked examples (combined with self-explanation prompts), completing problems with increasingly more blanks that learners have to fill in, to solving conventional problems.

However, further, and applied, research is needed to establish a solid foundation for the practical use of such training sequences for the acquisition of complex cognitive skills. Another strategy for optimizing instructional guidance in relation to the increasing knowledge levels of learners is adaptive task selection based on measures of performance and mental effort (cf. Corbalan, Kester, \& Van Merriënboer, 2006; Kalyuga, 2006; Salden, Paas, \& Van Merriënboer, 2006). Process-oriented worked examples can be part of the task databases from which learning tasks are selected and can be used when measures show that learners need very high levels of instructional support (cf. Corbalan et al., 2006).

In sum, this study has shown that process-oriented worked examples can initially foster learning, but start to hamper learning when the process information is known by students and becomes redundant. Future research is necessary to investigate how strategies for delivering sequences of worked examples to learners can be further optimized. 


\section{References}

Atkinson, R. K., Derry, S. J., Renkl, A., \& Wortham, D. (2000). Learning from examples: Instructional principles from the worked examples research. Review of Educational Research, 70, 181-214.

Atkinson, R. K., Renkl, A., \& Merrill, M. M. (2003). Transitioning from studying examples to solving problems: Effects of self-explanation prompts and fading worked-out steps. Journal of Educational Psychology, 95, 774-783.

Ayres, P. (2006). Using subjective measures to detect variations of intrinsic load within problems. Learning and Instruction, 16, 389-400.

Chandler, P., \& Sweller, J. (1991). Cognitive load theory and the format of instruction. Cognition and Instruction, 8, 293-332.

Chi, M. T. H., Bassok, M., Lewis, M. W., Reimann, P., \& Glaser, R. (1989). Self-explanations: How students study and use examples in learning to solve problems. Cognitive Science, $13,145-182$.

Cohen, J. (1988). Statistical power analysis for the behavioral sciences ( $2^{\text {nd }}$ ed.). Hillsdale, NJ: Erlbaum.

Cooper, G., Tindall-Ford, S., Chandler, P., \& Sweller, J. (2001). Learning by imagining. Journal of Experimental Psychology: Applied, 7, 68-82.

Corbalan, G., Kester, L., \& Van Merriënboer, J.J.G. (2006). Towards a personalized task selection model with shared instructional control. Instructional Science, 34, 399-422.

Cowan, N. (2001). The magical number 4 in short-term memory: A reconsideration of mental storage capacity. Behavioral \& Brain Sciences, 24, 87-114.

DesignSoft, Inc. (2002). TINA Pro (Version 6) [Computer software]. Available from http://www.tina.com. 
Ericsson, K. A., \& Simon, H. A. (1993). Protocol analysis: Verbal reports as data (Rev. ed.). Cambridge, MA: MIT Press.

Gerjets, P., Scheiter, K., \& Catrambone, R. (2006). Can learning from modular worked examples be enhanced by providing instructional explanations and prompting self-explanations? Learning and Instruction, 16, 104-121.

Gott, S. P., Parker Hall, E., Pokorny, R. A., Dibble, E., \& Glaser, R. (1993). A naturalistic study of transfer: Adaptive expertise in technical domains. In D. K. Detterman and R. J. Sternberg (Eds.), Transfer on trial: Intelligence, cognition, and instruction (pp. 258-288). Norwood, NJ: Ablex.

Große, R., \& Renkl, A. (2006). Effects of multiple solution methods in mathematics learning. Learning and Instruction, 16, 122-138.

Kalyuga, S. (2006). Rapid cognitive assessment of learners' knowledge structures. Learning and Instruction, 16, 1-11.

Kalyuga, S., Ayres, P., Chandler, P., \& Sweller, J. (2003). The expertise reversal effect. Educational Psychologist, 38, 23-32.

Kalyuga, S., Chandler, P., Tuovinen, J. E., \& Sweller, J. (2001). When problem solving is superior to studying worked examples. Journal of Educational Psychology, 93, 579-588.

Leahy, W., \& Sweller, J. (2005). Interactions among the imagination, expertise reversal, and element interactivity effects. Journal of Experimental Psychology: Applied, 11, 266-276.

Mayer, R. E., \& Wittrock, M. C. (1996). Problem-solving transfer. In D. C. Berliner, \& R. C. Calfee (Eds.), Handbook of Educational Psychology (pp. 47- 62). New York: Macmillan.

Miller, G. A. (1956). The magical number seven, plus or minus two: Some limits on our capacity to process information. Psychological Review, 63, 81-97.

Ohlsson, S., \& Rees, E. (1991). The function of conceptual understanding in the learning of 
arithmetic procedures. Cognition and Instruction, 8, 103-179.

Paas, F. (1992). Training strategies for attaining transfer of problem-solving skill in statistics: A cognitive load approach. Journal of Educational Psychology, 84, 429-434.

Paas, F., Renkl, A., \& Sweller, J. (2003). Cognitive load theory and instructional design: Recent developments. Educational Psychologist, 38, 1-4.

Paas, F., Tuovinen, J. E., Tabbers, H., \& Van Gerven, P. W. M. (2003). Cognitive load measurement as a means to advance cognitive load theory. Educational Psychologist, 38, 63-71.

Paas, F., \& Van Gog, T. (2006). Optimising worked example instruction: Different ways to increase germane cognitive load. Learning and Instruction, 16, 87-91.

Paas, F., \& Van Merriënboer, J. J. G. (1993). The efficiency of instructional conditions: An approach to combine mental-effort and performance measures. Human Factors, 35, 737743.

Paas, F., \& Van Merriënboer, J. J. G. (1994). Variability of worked examples and transfer of geometrical problem-solving skills: A cognitive-load approach. Journal of Educational Psychology, 86, 122-133.

Renkl, A. (1997). Learning from worked-out examples: a study on individual differences. Cognitive Science, 21, 1-29.

Renkl, A. (2002). Worked-out examples: Instructional explanations support learning by selfexplanations. Learning and Instruction, 12, 529-556.

Renkl, A., \& Atkinson, R. K. (2003). Structuring the transition from example study to problemsolving in cognitive skills acquisition: A cognitive load perspective. Educational Psychologist, 38, 15-22.

Salden, R. J. C. M., Paas, F., \& van Merriënboer, J. J. G. (2006). Personalised adaptive task 
selection in Air Traffic Control: Effects on training efficiency and transfer. Learning and Instruction, 16, 350-362.

Schneider, W., \& Shiffrin, R. M. (1977). Controlled and automatic human information processing: I. Detection, search, and attention. Psychological Review, 84, 1-66.

Sweller, J. (1988). Cognitive load during problem solving: Effects on learning. Cognitive Science, 12, 257-285.

Sweller, J., Van Merriënboer, J. J. G., \& Paas, F. (1998). Cognitive architecture and instructional design. Educational Psychology Review, 10, 251-295.

Van Gog, T., Paas, F., \& Van Merriënboer, J. J. G. (2004). Process-oriented worked examples: Improving transfer performance through enhanced understanding. Instructional Science, $32,83-98$.

Van Gog, T., Paas, F., \& Van Merriënboer, J. J. G. (2006). Effects of process-oriented worked examples on troubleshooting transfer performance. Learning and Instruction, 16, 154164.

Van Gog, T., Paas, F., Van Merriënboer, J. J. G., \& Witte, P. (2005). Uncovering the problemsolving process: Cued retrospective reporting versus concurrent and retrospective reporting. Journal of Experimental Psychology: Applied, 11, 237-244.

Van Merriënboer, J. J. G., \& Krammer, H. P. M. (1990). The "completion strategy" in programming instruction: Theoretical and empirical support. In S. Dijkstra, B. H. A. M. Van Hout-Wolters, \& P. C. Van der Sijde (Eds.), Research on instruction: Design and effects (pp. 45-61). Englewood Cliffs, NJ: Educational Technology Publications.

Van Merriënboer, J. J. G, Schuurman, J. G., De Croock, M. B. M., \& Paas, F. (2002). Redirecting learners' attention during training: Effects on cognitive load, transfer test performance and training. Learning and Instruction, 38, 11-39. 
Van Merriënboer, J. J. G., \& Sweller, J. (2005). Cognitive load theory and complex learning: Recent developments and future directions. Educational Psychology Review, 17, 147177.

Yeo, G. B., \& Neal, A. (2004). A multilevel analysis of effort, practice, and performance: Effects of ability, conscientiousness, and goal orientation. Journal of Applied Psychology, 89, 231-247. 
Table 1

Means and Standard Deviations of Prior Knowledge (0-10), Performance (0-3), Mental Effort (1-9), Efficiency (based on z-scores of Performance and Effort), and Time-on-Task (min.) per Condition

\begin{tabular}{|c|c|c|c|c|c|c|c|c|}
\hline & \multicolumn{2}{|c|}{ Product-Product } & \multicolumn{2}{|c|}{ Process-Process } & \multicolumn{2}{|c|}{ Product-Process } & \multicolumn{2}{|c|}{ Process-Product } \\
\hline & $M$ & $S D$ & $M$ & $S D$ & $M$ & $S D$ & $M$ & $S D$ \\
\hline Prior knowledge & 5.10 & .70 & 5.20 & 1.08 & 4.75 & 1.31 & 4.75 & 1.28 \\
\hline Performance Test 1 & 1.70 & .59 & 1.75 & .47 & 1.70 & .45 & 1.87 & .44 \\
\hline Mental effort Test 1 & 5.30 & 1.25 & 4.49 & 1.56 & 5.56 & .98 & 5.16 & 1.32 \\
\hline Efficiency Test 1 & $-.17^{\mathrm{A}}$ & 1.22 & $.34^{\mathrm{B}}$ & 1.02 & $-.31^{\mathrm{A}}$ & .84 & $.15^{\mathrm{B}}$ & 1.10 \\
\hline Performance Test 2 & 2.23 & .48 & 1.93 & .45 & 2.28 & .56 & 2.45 & .53 \\
\hline Mental effort Test 2 & 4.55 & 1.70 & 4.39 & 1.93 & 4.64 & 1.17 & 4.73 & 1.24 \\
\hline Efficiency Test 2 & .02 & .99 & $-.30 *$ & 1.06 & .05 & .94 & $.24 *$ & 1.10 \\
\hline Time-on-task Training 1 & 3.35 & .50 & 3.31 & .61 & 3.47 & .71 & 3.49 & .64 \\
\hline Time-on-task Training 2 & 1.35 & .51 & 1.51 & .56 & 1.94 & .77 & 1.19 & .46 \\
\hline Time-on-task Test 1 & 5.08 & 1.20 & 4.99 & 1.51 & 4.83 & 1.29 & 4.87 & 1.45 \\
\hline Time-on-task Test 2 & 2.93 & .58 & 3.04 & 1.09 & 3.37 & 1.11 & 3.15 & .95 \\
\hline
\end{tabular}

Efficiency Test 2: * marks significant $(\mathrm{p}<.05)$ differences between those conditions. 


\section{Figure Captions}

Figure 1. A product-oriented worked example. Note for the reader: In the diagram, AM= Ampère measurement point, $\mathrm{SW}=$ switch, $\mathrm{V}=$ voltage source, $\mathrm{R}=$ resistor. $\mathrm{In}$ the text, the Multimeter and screwdriver refer to TINA Pro software functionalities for measuring and repairing respectively.

Figure 2. A process-oriented worked example. Note for the reader: In the diagram, AM= Ampère measurement point, $\mathrm{SW}=$ switch, $\mathrm{V}=$ voltage source, $\mathrm{R}=$ resistor. $\mathrm{In}$ the text, the Multimeter and screwdriver refer to TINA Pro software functionalities for measuring and repairing respectively. 


\section{Product-Oriented Worked Example}

1. The total current should be: $I_{t}=I_{1}+I_{2}+I_{3}+I_{4}$ or:

${ }_{t}=\frac{U}{R_{1}}+\frac{U}{R_{2}}+\frac{U}{R_{3}}+\frac{U 9 \mathrm{~V}}{R_{4} 1 \bar{k} \Omega}+\frac{9 \mathrm{~V}}{500 \Omega}+\frac{9 \mathrm{~V}}{2 \mathrm{k} \Omega}+\frac{9 \mathrm{~V}}{500 \Omega}$

$=9 m A+18 m A+4.5 m A+18 m A=49.5 m A$

Hence, you should measure: $\mathrm{AM} 1=9 m A \quad \mathrm{AM} 2=18 m A$

$$
\mathrm{AM} 3=4.5 \mathrm{~mA} \quad \mathrm{AM} 4=18 \mathrm{~mA}
$$

$\mathrm{AM} 5=49.5 m A$

2. Go to T\&M $\rightarrow$ Multimeter, and measure the current at AM1, AM2, AM3, AM4 en AM5. You see:

$\mathrm{AM} 1=9 \mathrm{~mA}$

$$
\mathrm{AM} 2=18 \mathrm{~mA}
$$

$\mathrm{AM} 3=9 n A$

$\mathrm{AM} 4=18 m A$

$\mathrm{AM} 5=45 \mathrm{~mA}$

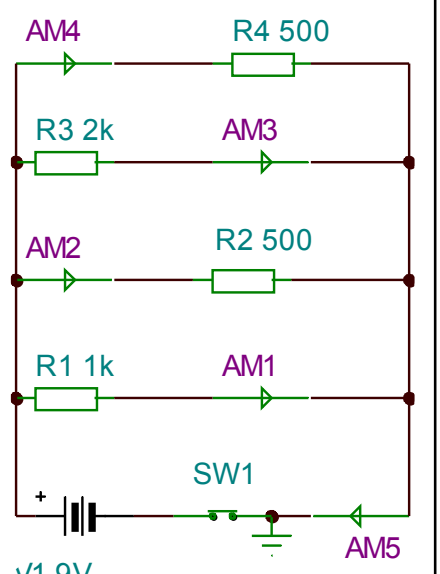

V1 9V

3. The calculation and measurement do not correspond, something is wrong.

4. $I_{3}=9 n A \rightarrow \mathrm{R} 3$ is open.

5. Repair R3 using the screwdriver with the $\checkmark$.

6. Go to T\&M $\rightarrow$ Multimeter, and measure the current at AM1, AM2, AM3, AM4 en AM5. You see:

$\mathrm{AM} 1=9 \mathrm{~mA} \quad \mathrm{AM} 2=18 \mathrm{~mA} \quad \mathrm{AM} 3=4.5 \mathrm{~mA} \quad \mathrm{AM} 4=18 \mathrm{~mA} \quad \mathrm{AM} 5=49.5 \mathrm{~mA}$

7. The measures correspond, the circuit now functions correctly. 


\section{Process-Oriented Worked Example}

1. Using Ohm's law, determine how this circuit should function.

In parallel circuits, the total current $\left(I_{t}\right)$ equals the sum of the currents in the parallel branches $\left(I_{1}, I_{2}\right.$, etc.)

Therefore, the total current should be: $I_{t}=I_{1}+I_{2}+I_{3}+I_{4}$

or:

$t_{t}=\frac{U}{R_{1}}+\frac{U}{R_{2}}+\frac{U}{R_{3}}+\frac{U 9 \mathrm{~V}}{R_{4} 1 \bar{k} \Omega}+\frac{9 \mathrm{~V}}{500 \Omega}+\frac{9 \mathrm{~V}}{2 \mathrm{k} \Omega}+\frac{9 \mathrm{~V}}{500 \Omega}$

$=9 m A+18 m A+4.5 m A+18 m A=49.5 m A$

Hence, you should measure:

$\mathrm{AM} 1=9 \mathrm{~mA} \quad \mathrm{AM} 2=18 \mathrm{~mA} \quad \mathrm{AM} 3=4.5 m A \quad \mathrm{AM} 4=18 m A \quad \mathrm{AM} 5=49.5 \mathrm{~mA}$

2. Use the Multimeter to measure how the circuit actually functions.

Go to T\&M $\rightarrow$ Multimeter, and measure the current at AM1, AM2, AM3, AM4 en AM5.

You see:

$\mathrm{AM} 1=9 m A \quad \mathrm{AM} 2=18 m A \quad \mathrm{AM} 3=9 n A \quad \mathrm{AM} 4=18 m A \quad \mathrm{AM} 5=45 m A$

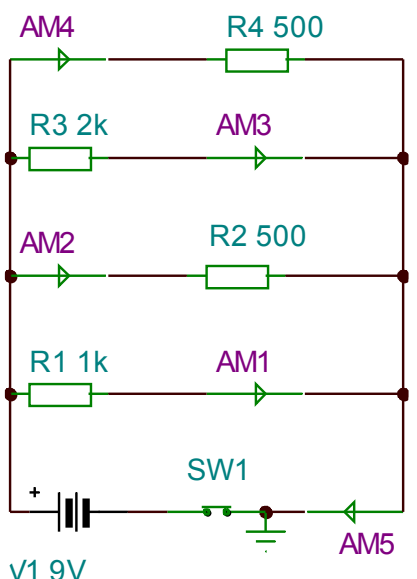

3. Compare the outcomes of 1 and 2

The calculation and measurement do not correspond, something is wrong.

4. Determine which component is faulty and what the fault is

In case of infinitely low current in a parallel branch, the resistance in that branch is infinitely high, very likely that resistor is open (but possibly it is another component or the wire that's open), unless there is infinitely low current in the entire circuit, in that case there is an infinitely high resistance somewhere outside the parallel branches, very likely the battery, switch, or wire outside the branches is open.

There is only infinitely low current in a branch $\left(I_{3}=9 n A\right)$, not in the entire circuit, so likely R3 is open.

\section{Repair the component}

Repair R3 using the screwdriver with the $\checkmark$.

6. Measure again, there might be more faults

Go to T\&M $\rightarrow$ Multimeter, and measure the current at AM1, AM2, AM3, AM4 en AM5. You see:

$\mathrm{AM} 1=9 \mathrm{~mA} \quad \mathrm{AM} 2=18 \mathrm{~mA} \quad \mathrm{AM} 3=4.5 \mathrm{~mA} \quad \mathrm{AM} 4=18 \mathrm{~mA} \quad \mathrm{AM} 5=49.5 \mathrm{~mA}$

7. Do the measures correspond to the calculations at step 1 ?

(Yes $\rightarrow$ problem solved $\quad$ No $\rightarrow$ Start again at step 4.)

The measures correspond, the circuit now functions correctly. 